\title{
Neurogenesis in Adult Subventricular Zone
}

\author{
Arturo Alvarez-Buylla1 and Jose Manuel García-Verdugo² \\ 1 Department of Neurological Surgery, Brain Tumor Research Center, San Francisco, California 94143-0520, and \\ 2Department of Cellular Biology, Faculty of Biology, University of Valencia, Valencia, Spain 46100
}

Much excitement has been generated by the identification of adult brain regions harboring neural stem cells and their continual generation of new neurons throughout life. This is an important departure from traditional views of the germinal potential of the postnatal brain. However, a more profound paradigm shift may be emerging. Studies of adult neurogenesis in the subventricular zone (SVZ) have revealed unexpected properties of neuronal progenitors and new mechanisms of neuronal migration. Here we discuss some recent findings that examine the origin, migration, and function of SVZ-derived new neurons in adult brain and highlight areas that offer exiting opportunities for future research.
Along much of the lateral walls of the lateral ventricles lies the largest germinal zone of the adult mammalian brain, the SVZ (Doetsch and Alvarez-Buylla, 1996). In fully adult mammals, mew neurons born in the SVZ of adults migrate anteriorly into the olfactory bulb (OB), where they mature into local interneurons (Altman, 1969; Lois and Alvarez-Buylla, 1994; Kornack and Rakic, 2001; Pencea et al., 2001a) (Fig. 1). SVZ neural stem cells can be grown in culture with epidermal growth factor (EGF), fibroblast growth factor (FGF), or the two combined (Weiss et al., 1996; Temple and Alvarez-Buylla, 1999; Gage, 2000). As such, the SVZ represents an important reservoir of progenitors in the adult brain, perhaps harboring cell populations that could be used for neuroregenerative therapy. These findings dramatically change the way we think about the adult brain. However, a deeper paradigm shift may be emerging as these discoveries raised basic mechanistic questions not easily explained by classical views of brain development.

(1) Which cells give rise to new neurons in adult brain, and how is the production of these new neurons regulated? (2) How do the young neurons move through adult brain and find their way into the OB? (3) What is the function of neuronal replacement in the adult OB? Two decades ago, it was difficult to imagine that neurogenesis and neuronal migration could be studied in adult brain. However, the SVZ-OB system has become an attractive experimental model in which to study neural stem cells, neurogenesis, the migration of young neurons, and their differentiation and death. Moreover, the entire process raises basic questions about how neural circuits benefit from a constant exchange of neurons.

\section{Origins}

The continual production of new neurons in the adult SVZ suggests that neural stem cells persist within this germinal layer. The SVZ-ependymal region contains at least four different cell types defined by their morphology, ultrastructure, and molecular

This work was supported by National Institutes of Health Grants NS28478 and HD32116, by the Sandler Family supporting Foundation, and Fundació la Caixa. We thank Anthony Tramontin and Nader Sanai for their comments on this manuscript. Correspondence should be addressed to Dr. Alvarez-Buylla, Department of Neurological Surgery, Brain Tumor Research Center, Box 0520, 533 Parnassus Avenue, San Francisco, CA 94143-0520. E-mail: abuylla@itsa.ucsf.edu.

Copyright (C) 2002 Society for Neuroscience 0270-6474/02/220629-06\$15.00/0 markers (Doetsch et al., 1997) (for the organization of the SVZ, see Fig. 2). The young migrating neurons (type A cells) form chains ensheathed by astrocytes (type B cells). More spherical and highly proliferative precursors (type $\mathrm{C}$ cells) form clusters next to the chains of migrating A cells. The SVZ is largely separated from the ventricle cavity by a layer of ependymal cells (type E cells). B cells interact closely with E cells and occasionally contact the ventricle lumen. Whereas E cells have many long cilia, B cells contain a single short cilium (Doetsch et al., 1999b) similar to those of neural progenitors in the embryo.

In addition to $\mathrm{C}$ cells, which are labeled most frequently by $\left[{ }^{3} \mathrm{H}\right]$-thymidine injection, B and A cells, the SVZ astrocytes and young neurons respectively, also divide. It has been suggested that muticiliated E cells also divide in vivo and function as stem cells (Johansson et al., 1999). However, when labeled cells near the lateral wall of the lateral ventricle are analyzed with electron microscopy, no evidence of ependymal division is found (Doetsch et al., 1999a).

The division of $\mathrm{B}$ and $\mathrm{C}$ cells suggests that one or both of these cell types could be involved in the generation of the new neurons, the A cells. Because A cells, themselves, divide (Lois and Alvarez-Buylla, 1994; Menezes et al., 1995; Thomas et al., 1996), it was also formally possible that they simply generate more A cells. However, purified A cells in culture do not appear to be self renewing (Lim and Alvarez-Buylla, 1999). In contrast, a fraction enriched for $\mathrm{B} / \mathrm{C}$ cells gives rise to large colonies of A cells. Previous studies had noticed that the SVZ astrocytes divide, but it was thought that these cells were simply generating more glia. Quite unexpectedly, more recent work indicates that B cells, the SVZ astrocytes, are the primary precursors of new neurons (Doetsch et al., 1999a). After ablation of C and A cells with antimitotic drugs, SVZ astrocytes divide to generate new $\mathrm{C}$ cells that in turn generate A cells. Labeling specifically SVZ astrocytes with an avian retrovirus resulted in the generation of labeled neurons that migrated and integrate in the OB. Thus, under normal conditions and during regeneration, B cells seem to function as the primary precursors for the new neurons (Fig. 2). These cells are also capable of generating cells that grow as neural stem cells in vitro (Doetsch et al., 1999a).

SVZ astrocytes cultured in vitro can also generate FGF- and EGF-responsive neurospheres (Laywell et al., 2000). Interest- 
Figure 1. The SVZ-OB system. Schematic sagittal view of the adult rodent brain with the OB to the left and the cerebellum $(C B)$ to the right. The SVZ is along the lateral wall of the lateral ventricle $(L V$, blue $)$. New neurons are constantly produced throughout the SVZ. The young neurons (A cells) (Fig. 3) become aligned into long chains (red lines) (Fig. 2) that form a complex network of interconnected paths throughout the SVZ. Many of these chains in the anterior SVZ connect with the RMS, which leads young neurons into the core of the olfactory bulb. Within the olfactory bulb, cells disperse radially (dotted lines) as individual cells and complete their differentiation into granule and periglomerular interneurons. $N C$, Neocortex; $c c$, corpus callosum.

ingly, this same study has shown that mouse astrocytes from cortex, cerebellum, and spinal cord can also behave as stem cells in vitro, but only when isolated before postnatal day 10 . Recent work in the adult subgranular layer of the hippocampus indicates that in this region, too, astrocytes function as the primary precursors for new granule neurons (Seri et al., 2001). The neurogenic potential of cells with astrocytic properties is surprising given the previously unchallenged idea that neuroglia develop from a lineage separate from that of neurons. Astrocytes are derived from radial glia during development. In some species, including the canary, radial glia are retained into adult life, serving as the primary precursors of new neurons (Alvarez-Buylla et al., 1990b). Emerging data also indicate that radial glia are neural stem cells in the developing mammalian neocortex (Malatesta et al., 2000; Miyata et al., 2001; Noctor et al., 2001). Muller cells have also been identified as neural precursors in the developing retina (Fischer and Reh, 2001). Together, these findings have led to the proposition that neural stem cells lie within the neuroepithelial-radial glia-astrocyte lineage (Alvarez-Buylla et al., 2001).

Neurogenesis in the adult brain is restricted to particular niches. Is it the astrocytes, the microenvironment, or both that create an adult brain germinal region? The identification of reliable molecular markers to distinguish terminally differentiated astrocytes from those that can function as neural stem cells remains an important problem for future research. Most of the signaling molecules that allow neurogenesis to occur in the SVZ also remain to be discovered. One signaling pathway, however, has been recently identified. Local neutralization of BMP signaling, a neurogenesis inhibitor, by ependymal noggin may be critical for SVZ neurogenesis (Lim et al., 2000) (Fig. 2). Adult neurogenesis likely results from the interplay of microenvironment with specific subtypes of astrocytes.

The regulation of proliferation in the SVZ is another particularly interesting problem. The symmetry of B cell division remains unknown, as does the number of times $\mathrm{C}$ cells divide before A cell production. The cell cycle of the different cell types in the SVZ needs to be determined. Previous estimates of cell cycle duration in the SVZ assumed that the SVZ is composed of a homogenous population of nonmigratory dividing cells (Morshead et al., 1994). These assumptions are not met in the SVZ, particularly given the rapid tangential migration of dividing A cells. More accurate methods are required to establish the cell cycle duration for the specific cell types in the SVZ.
Growth factors also probably play an important role in the regulation of proliferation in the SVZ. EGF, TGF $\alpha$, and FGF can stimulate the proliferation of SVZ cells in vivo (Morshead et al., 1994; Craig et al., 1996; Kuhn et al., 1997; Tropepe et al., 1997). SVZ cells respond to EGF, FGF-forming neurospheres that have characteristics of neural stem cells in vitro (Morshead et al., 1994; Weiss et al., 1996). Interestingly, growth factor-amplified SVZ cells appear to acquire the ability to function as progenitors for other organs as well (Vescovi et al., 2001). The in vivo role of growth factors and their receptors is, however, poorly understood. Consequently, the identity of the EGF-responsive cells in vivo is controversial. Whereas earlier work suggest that the EGFresponsive cells are relatively quiescent (Morshead et al., 1994), recent experiments suggest that EGF induces the rapidly dividing transient amplifying cells (C cells) to behave as stem cells in vitro (Doetsch et al., 2001). The FGF-responsive cells have not yet been identified. Other molecules in concert with classical growth factors may also regulate proliferation in the SVZ. SVZ astrocytes express ligands for EphB2. Infusion of EphB2 or ephrinB2 receptor bodies into the brain increases the proliferation of SVZ cells and induces many B cells to contact the ventricle (Conover et al., 2000). We are still far from understanding how precise numbers of new neurons and glial cells are generated in the SVZ. This information is important to determine the dynamics of cell generation and to draw a precise lineage from the dividing SVZ stem cells, through the transient amplifying $\mathrm{C}$ cells to the final progeny of young neurons.

\section{Migration}

In adult mice, the SVZ is millimeters away from the OB; quite a journey for a cell that is just $10-30 \mu \mathrm{m}$ long. The problem is further compounded if we consider that A cells, the SVZ neuroblasts, originate throughout most of the lateral wall of the lateral ventricle and traverse a complex network of interconnected paths before joining the rostral migratory stream (RMS) (Doetsch and Alvarez-Buylla, 1996) (Fig. 1). A similar migration has now been described in much larger brains, including those of primates (Kornack and Rakic, 2001; Pencea et al., 2001a). It has also been suggested that similar migrations may occurs in the infant human brain (Weickert et al., 2000). In these large brains, the migration of SVZ derived cells is impressively long. How do these cells move and orient over such long distances and traverse the dense parenchyma of the adult brain? A migration from the SVZ to 


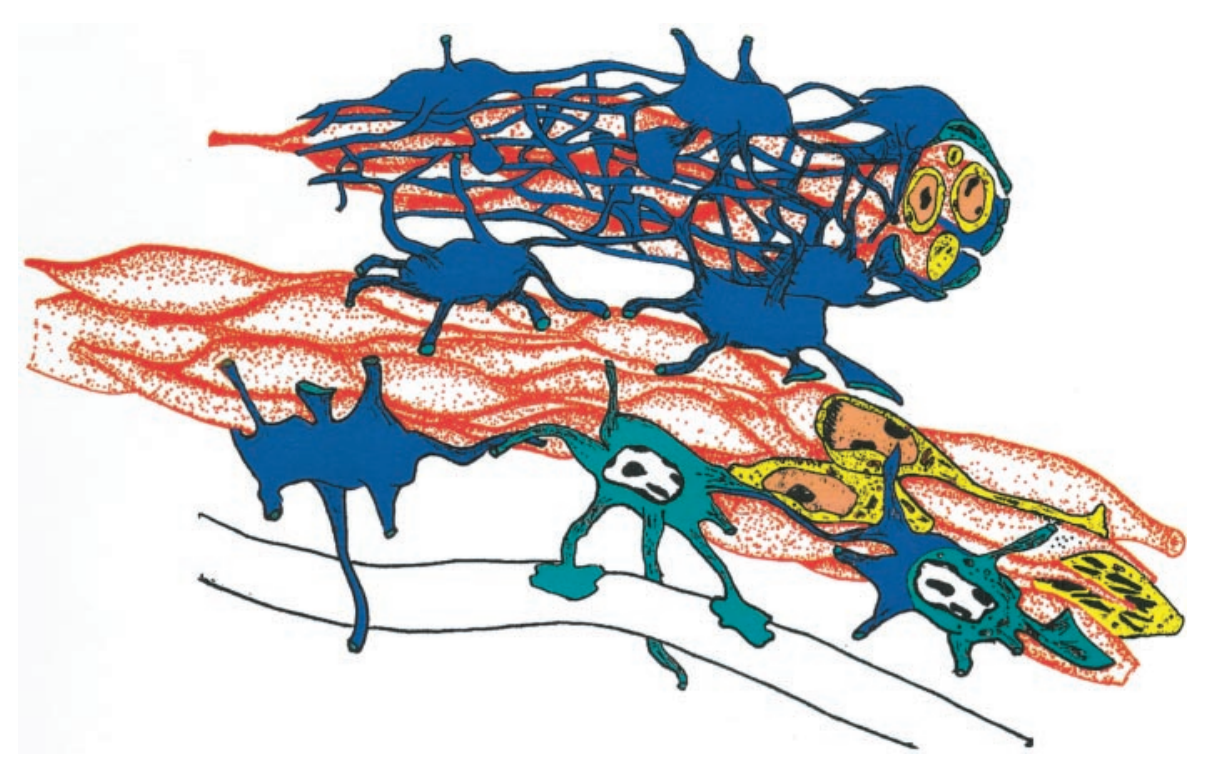

Figure 2. Chain migration. Young neurons within the SVZ network and in the RMS migrate along each other to form long chains. Chains of migrating cells (red) are ensheathed by glial cells (blue) that have astrocytic characteristics, including dense bundles of GFAP-containing intermediate filaments and endings on blood vessel (below). Two chains are illustrated here. In the bottom chain only some of the astrocytes have been drawn to illustrate the tight organization of A cell into chains. The intracellular characteristics of some of the B cells (light blue) and A cells (yellow) are illustrated. An A cell in mitosis is illustrated in the bottom chain to the right. neocortex has also been suggested (Gould et al., 1996; Magavi et al., 2000), but this migration has not been demonstrated.

In adult rodent SVZ and RMS, A cells move along each other, forming chains (Fig. 3) (Lois et al., 1996). A cells have an elongated morphology with a prominent leading process tipped by a growth cone (Kishi, 1987; Lois and Alvarez-Buylla, 1994; Wichterle et al., 1997). In chains reconstituted in vitro, neuroblasts move in incremental steps at average speeds of $\sim 120 \mu \mathrm{m} / \mathrm{hr}$ (Wichterle et al., 1997). The cellular machinery that propels young neurons at these high speeds is not understood. It is likely that microtubule polymerization and depolymerization plays an important role in both the exploratory behavior and net translocation that occurs during a step. Doublecortin, a microtubuleassociated protein important for neuronal migration in development, is expressed prominently by cells in chains of the RMS (Gleeson et al., 1999), suggesting that the migration to the OB in the adult shares key molecular players with migration in the embryo. The prominent growth cone and the active extension and retraction of the leading process of A cells (Wichterle et al., 1997), suggest that these cells may use some of the locomotory mechanisms also used by growing axons. Accordingly, collapsin response-mediated protein 4 , a molecule involved in axonal guidance, is present in the migrating A cells (Nacher et al., 2000). Migration of neurons and the growth of axons could differ in that the former incorporates a mechanism to shuttle the cell body into the leading process, resulting in the net translocation of the cell. How the A cell cytoskeleton functions during migration and what types of signals trigger the cell to advance a step are particularly interesting problems for future research.

As mentioned above, chains of migrating A cells are ensheathed by astrocytes (B cells) (Figs. 2, 3) (Jankovski and Sotelo, 1996; Lois et al., 1996; Peretto et al., 1997). The function of the glial tubes is not known. Astrocytes are not essential for chain migration (Wichterle et al., 1997), but factors secreted by astrocytes appear to enhance the migration of SVZ neuroblasts (Mason et al., 2001). These ensheathing astrocytes are likely to play important roles. In addition to enhancement of migration, the glial cells around chains may also support the survival and/or provide directional information to the A cells. Additionally, these tubes may prevent A cells from prematurely escaping normal migratory routes.
Work has begun to identify cell surface adhesion molecules that may be important for chain migration. $\alpha 6 \beta 1$ integrin appears to be required for chain migration of type A cells (Jacques et al., 1998). Polysialylated form of neural cell adhesion molecule (PSANCAM) is expressed along the RMS (Bonfanti and Theodosis, 1994) in migrating A cells (Rousselot et al., 1995), and the rostral migration of A cells is severely disrupted in animals lacking NCAM or PSA (Tomasiewicz et al., 1993; Cremer et al., 1994; Ono et al., 1994). Although initial observations had suggested that PSA was essential for chain migration (Hu et al., 1996), more recent work indicates that A cells lacking PSA are less effective in their migration, but capable of forming chains and moving along the RMS (Cremer et al., 1994). This study shows that PSA is critically important for the organization of B cell gliotubes in the RMS. PSA-NCAM may prevent A cells from establishing tight contacts with glial cells that may hinder them in their long journey. The extracellular matrix also contributes to the migratory environment of the RMS. Tenascin and chondroitin sulfatecontaining proteoglycans have been shown to be present in the RMS (Thomas et al., 1996). Further work is needed to understand the interplay of surface molecules with the extracellular matrix during chain migration.

The directionality of migration over the long distance between the SVZ and the OB is perhaps one of the most fascinating problems in this system. Presence of the OB is not required for the rostral migration of A cells (Kirschenbaum et al., 1999), suggesting that, if the OB secretes chemoattractants, these factors are nonessential for the rostral migration. Instead, it has been suggested that chemorepulsion mediated by Slit-Robo signaling may be involved in the migration of young neurons in the RMS (Hu, 1999; Wu et al., 1999). There is, however, no information in vivo regarding the role of Slits, and it is difficult to imagine how stable gradients of repulsive agents can be established over such a long and complex migratory route. Moreover, it has been suggested that the source of Slit is the septum, which lies in the medial wall of the lateral ventricle, opposite to where the majority of migration occurs. Slits, instead may serve as general inhibitors of migration (Mason et al., 2001), perhaps preventing SVZ neuroblasts from migrating into certain regions of the brain. The directional mechanism of SVZ and RMS migration remains wide 
Figure 3. Organization and lineage in the SVZ. Left, Cross section of the anterior rodent brain indicating the location of the SVZ on the lateral wall of the LV. On the right is the cellular composition and organization of the SVZ. Chains of young neurons (A cells, red) are surrounded by B cells (blue) that have astrocytic characteristics and form tube-like structures. Clusters of highly proliferative $\mathrm{C}$ cells are associated with the chains of A cells. Ependymal $(E)$ cells form an epithelial layer that separates the SVZ from the ventricle $(L V)$. B cells generate transient amplifying $\mathrm{C}$ cells that generate the A cells (top). Bottom left, BMPs inhibit neurogenesis and favor glial differentiation (blue). Noggin secreted by ependymal cells binds BMPs and releases some B cells to become neurogenic and produce $\mathrm{C}$ (green) and $\mathrm{A}($ red $)$ cells.

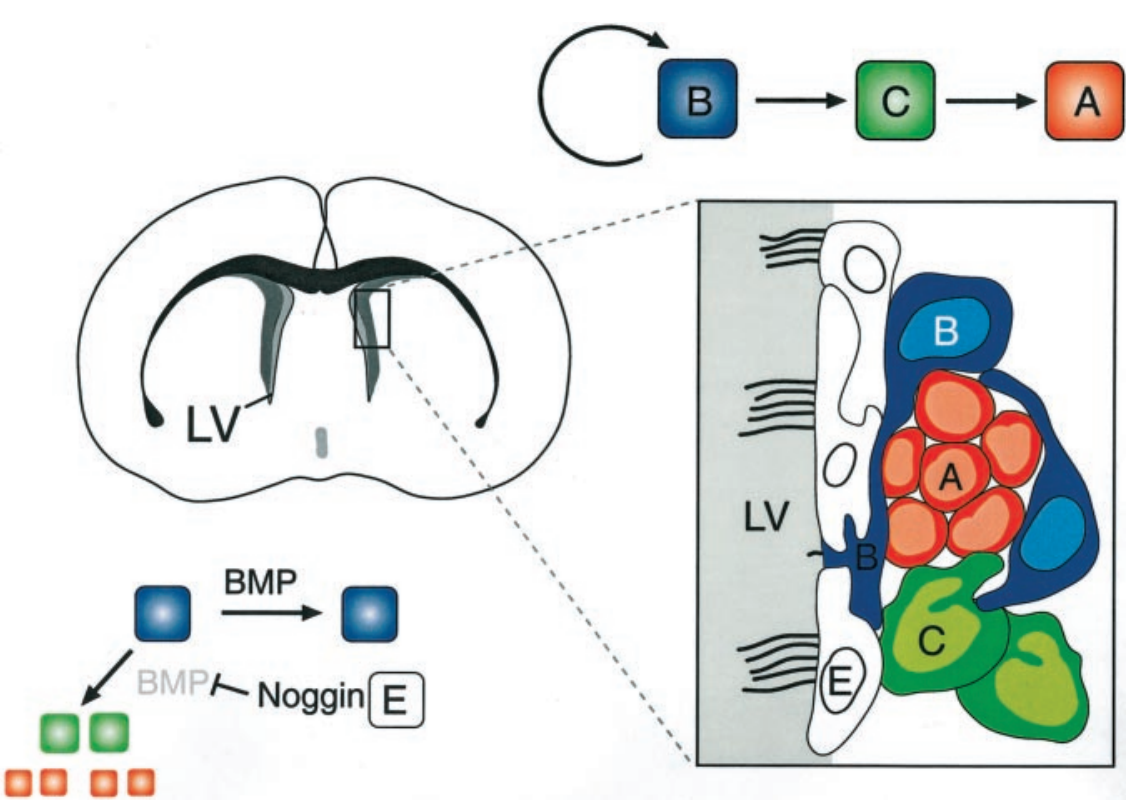

open. Understanding this process may yield novel mechanisms of neuronal orientation.

Once cells reach the core of the OB, they separate from the chains, individually migrate to more superficial layers, and differentiate into granule and periglomerular neurons. Nothing is known about the signals in the $\mathrm{OB}$ that induce this change of migration pattern. The mechanism of radial migration within the bulb is also not known. Interestingly, in the adult OB, radial glia are no longer present, raising the question of what guides these young neurons from the OB core to more superficial layers.

\section{Function}

Thousands of young neurons migrate (A cells) into the OB every day (Lois and Alvarez-Buylla, 1994), but only a fraction of these cells survive to complete their differentiation. This process is even more conspicuous in the early postnatal brain, where the RMS is massive (Luskin, 1993). Why are all these new neurons incorporated into the olfactory system during postnatal life?

In the adult hippocampus (Barnea and Nottebohm, 1994; Kempermann et al., 1997; Gould et al., 1999a) and the song control nuclei in adult birds (Nottebohm, 1985; Alvarez-Buylla et al., 1990a), two systems where adult neuronal incorporation has been extensively studied, it has been suggested that new neurons participate in plasticity and learning. Much less is known about the function of new neurons in the OB of postnatal animals. Optimal olfactory circuitry may be assembled by the incorporation of neurons when olfactory circuits are already responding to environmental signals. The continuous replacement of neurons in the OB may allow for adjustment of olfactory circuitry as the environment or relevance of odors change.

Naris closure decreases the recruitment of new neurons to the OB (Frazier-Cierpial and Brunjes, 1989; Corotto et al., 1994). It is possible that only granule cells connected to relatively active mitral or tufted cells survive, whereas all others undergo apoptosis. Recent work indicates that soon after new granule cells develop synaptic connections in the $\mathrm{OB}$, there is a period of intense cell death, perhaps reflecting this selection process (Petreanu and Alvarez-Buylla, 2001). What could be the advantage of continual replacement of granule cells? Granule cell activity is known to extensively shape the activity of mitral and tufted cells.
Modeling experiments indicate that selection of new granule cells based on their level of activity alone could continually redistribute odorant representations across the OB (Cecchi et al., 2001). This model predicts a remarkable improvement in olfactory discrimination by maximizing differences between similar odors. Studies in NCAM $(-/-)$ mice, in which the number of newly formed SVZ cells that reach the OB from birth is severely reduced, olfactory discrimination between odors is impaired, but odor sensitivity and olfactory memory appear normal (Gheusi et al., 2000). Thus, experimental and theoretical approaches are beginning to suggest that new neurons in the OB have some role in olfactory discrimination.

Neurogenesis may in adult animals may allow brain circuitry involved in sexual behavior to be modified. In birds, steroid hormones play important roles in regulating the survival of newly generated neurons in song control nuclei (Rasika et al., 1994, 1999; Burek et al., 1995; Hidalgo et al., 1995). Similarly, in the adult hippocampus, estrogen appears to increase the number of dividing cells in the subgranular layer (Tanapat et al., 1999). New interneurons are also added to the accessory OB (Bonfanti et al., 1997), a region known to process olfactory information related to sexual behavior. Interestingly, recent work in prairie voles shows a dramatic increase in the number of dividing cells in the RMS during estrous (Smith et al., 2001). BDNF promotes the survival of A cells (Kirschenbaum and Goldman, 1995; Pencea et al., 2001b). As in birds, the effects of steroid hormones on the survival of the new neurons may be mediated through this trophic factor (Rasika et al., 1999). However, BDNF is thought to function as a trophic factor for neurons that have matured and are becoming integrated into functional circuits. It is, therefore, very intriguing that the survival of a population of migrating precursors should be regulated in this manner. Moreover, A cells far outnumber the new neurons that become incorporated in the $\mathrm{OB}$; why then is regulation of their survival so critical?

This is just the beginning of our understanding of what is, perhaps, the most intriguing problem: the role of the new neurons in the OB. More sensitive behavioral models to test olfactory discrimination are needed. Animal models in which only a subpopulation of granule cells born postnatally could be ablated are 
also required so that developmental history would not interfere with interpretation of behavior. In addition, we need a better understanding of the contribution of the new neurons to electrophysiological changes in the OB.

\section{Future perspective}

The SVZ-OB system offers a unique opportunity to study, in an adult organism, the origin, migration, and integration of new neurons into functional brain circuits. Here we separated the process into three topics that expose exciting mechanistic data that has recently emerged. The identification of SVZ astrocytes as neural stem cells is particularly intriguing. We may learn in the coming years how to identify those cells with astrocytic properties that can function as stem cells. This information may open new avenues for the isolation and genetic modification of stem cells derived from the postnatal brain. Studies of the molecular mechanisms of cell translocation and orientation during chain migration are also in their infancy. Very basic mechanisms may be discovered here, too, as the distances and speeds of migration baffle those accustomed to thinking of neuronal migration as a developmental process. Origin and migration are conceptually interrelated problems. It is likely that advances in our understanding on these two fronts will provide the essential ingredients for future studies to elucidate the function of newly generated cells. This last topic is by far the most challenging and probably hides behind fundamental principles of brain function.

\section{REFERENCES}

Altman J (1969) Autoradiographic and histological studies of postnatal neurogenesis. IV. Cell proliferation and migration in the anterior forebrain, with special reference to persisting neurogenesis in the olfactory bulb. J Comp Neurol 137:433-458.

Alvarez-Buylla A, Kirn JR, Nottebohm F (1990a) Birth of projection neurons in adult avian brain may be related to perceptual or motor learning. Science 249:1444-1446.

Alvarez-Buylla A, Theelen M, Nottebohm F (1990b) Proliferation "hot spots" in adult avian ventricular zone reveal radial cell division. Neuron 5:101-109.

Alvarez-Buylla A, Garcia-Verdugo JM, Tramontin AD (2001) A unified hypothesis on the lineage of neural stem cells. Nat Rev Neurosci 2:287-293.

Barnea A, Nottebohm F (1994) Seasonal recruitment of hippocampal neurons in adult free-ranging black-capped chickadees. Proc Natl Acad Sci USA 91:11217-11221.

Bonfanti L, Theodosis DT (1994) Expression of polysialylated neural cell adhesion molecule by proliferating cells in the subependymal layer of the adult rat, in its rostral extension and in the olfactory bulb. Neuroscience 62:291-305.

Bonfanti L, Peretto P, Merighi A, Fasolo A (1997) Newly-generated cells from the rostral migratory stream in the accessory olfactory bulb of the adult rat. Neuroscience 81:489-502.

Burek MJ, Nordeen KW, Nordeen EJ (1995) Estrogen promotes neuron addition to an avian song-control nucleus by regulating post-mitotic events. Dev Brain Res 85:220-224.

Cecchi GA, Petreanu LT, Alvarez-Buylla A, Magnasco MO (2001) Unsupervised learning and adaptation in a model of adult neurogenesis. J Comp Neurosci 11:175-182.

Conover JC, Doetsch F, García-Verdugo JM, Gale NW, Yancopoulos GD, Alvarez-Buylla A (2000) Disruption of Eph/ephrin signaling affects migration and cell proliferation in the subventricular zone of the adult mouse brain. Nat Neurosci 3:1091-1097.

Corotto FS, Henegar JR, Maruniak JA (1994) Odor deprivation leads to reduced neurogenesis and reduced neuronal survival in the olfactory bulb of the adult mouse. Neuroscience 61:739-744.

Craig CG, Tropepe V, Morshead CM, Reynolds BA, Weiss S, Van der Kooy D (1996) In vivo growth factor expansion of endogenous subependymal neural precursor cell populations in the adult mouse brain. J Neurosci 16:2649-2658.

Cremer H, Lange R, Christoph A, Plomann M, Vopper G, Roes J, Brown R, Baldwin S, Kraemer P, Scheff S, Barthels D, Rajewsky K, Wille W (1994) Inactivation of the N-CAM gene in mice results in size reduction of the olfactory bulb and deficits in spatial learning. Nature 367:455-459.

Doetsch F, Alvarez-Buylla A (1996) Network of tangential pathways for neuronal migration in adult mammalian brain. Proc Natl Acad Sci USA 93:14895-14900.

Doetsch F, Garcia-Verdugo JM, Alvarez-Buylla A (1997) Cellular composition and three-dimensional organization of the subventricular germinal zone in the adult mammalian brain. J Neurosci 17:5046-5061.

Doetsch F, Caille I, Lim DA, García-Verdugo JM, Alvarez-Buylla A (1999a) Subventricular Zone Astrocytes Are Neural Stem Cells in the Adult mammalian. Brain Cell 97:1-20.

Doetsch F, Garcia-Verdugo JM, Alvarez-Buylla A (1999b) Regeneration of a germinal layer in the adult mammalian brain. Proc Natl Acad Sci USA 96:11619-11624.

Doetsch F, Caille I, García-Verdugo JM, Alvarez-Buylla A (2001) EGF induces conversion of transyt amplifying neurogenic precursors into multipotential invasive cells in the adult brain. Soc Neurosci Abstr 894.4.

Fischer AJ, Reh TA (2001) Muller glia are a potential source of neural regeneration in the postnatal chicken retina. Nat Neurosci 4:247-252.

Frazier-Cierpial L, Brunjes PC (1989) Early postnatal cellular proliferation and survival in the olfactory bulb and rostral migratory stream of normal and unilaterally odor-deprived rats. J Comp Neurol 289:481-492.

Gage FH (2000) Mammalian neural stem cells. Science 287. 287:1433-1438.

Gheusi G, Cremer H, McLean H, Chazal G, Vincent JD, Lledo PM (2000) Importance of newly generated neurons in the adult olfactory bulb for odor discrimination. Proc Natl Acad Sci USA 97:1823-1828.

Gleeson JG, Lin PT, Flanagan L, Walsh C (1999) Doublecortin is a microtubule-associated protein and is expressed widely by migrating neurons. Neuron 23:257-271.

Gould E, Beylin A, Tanapat P, Reeves A, Shors TJ (1999a) Learning enhances adult neurogenesis in the hippocampal formation. Nat Neurosci 2:260-265.

Gould E, Reeves AJ, Graziano MSA, Gross CG (1999b) Neurogenesis in the neocortex of adult primates. Science 286:548-552.

Hidalgo A, Barami K, Iversen K, Goldman SA (1995) Estrogens and non-estrogenic ovarian influences combine to promote the recruitment and decrease the turnover of new neurons in the adult female canary brain. J Neurobiol 27:470-487.

$\mathrm{Hu} \mathrm{H}$ (1999) Chemorepulsion of neuronal migration by Slit2 in the developing mammalian forebrain. Neuron 23:703-711.

Hu HY, Tomasiewicz H, Magnuson T, Rutishauser U (1996) The role of polysialic acid in migration of olfactory bulb interneuron precursors in the subventricular zone. Neuron 16:735-743.

Jacques TS, Relvas JB, Nishimura S, Pytela R, Edwards GM, Streuli CH, ffrench-Constant C (1998) Neural precursor cell chain migration and division are regulated through different B1 integrins. Development 125:3167-3177.

Jankovski A, Sotelo C (1996) Subventricular zone-olfactory bulb migratory pathway in the adult mouse: cellular composition and specificity as determined by heterochronic and heterotopic transplantation. J Comp Neurol 371:376-396.

Johansson CB, Momma S, Clarke DL, Risling M, Lendahl U, Frisén J (1999) Identification of a neural stem cell in the adult mammalian central nervous system. Cell 96:25-34.

Kempermann G, Kuhn HG, Gage FH (1997) More hippocampal neurons in adult mice living in an enriched environment. Nature 386:493-495.

Kirschenbaum B, Goldman SA (1995) Brain-derived neurotrophic factor promotes the survival of neurons arising from the adult rat forebrain subependymal zone. Proc Natl Acad Sci USA 92:210-214.

Kirschenbaum B, Doetsch F, Lois C, Alvarez-Buylla. A (1999) Adult subventricular zone neuronal precursors continue to proliferate and migrate in the absence of the olfactory bulb. J Neurosci 19:2171-2180

Kishi K (1987) Golgi studies on the development of granule cells of the rat olfactory bulb with reference to migration in the subependymal layer. J Comp Neurol 258:112-124.

Kornack DR, Rakic P 2001 The generation, migration, and differentiation of olfactory neurons in the adult primate brain. Proc Natl Acad Sci USA 98:4752-4757.

Kuhn HG, Winkler J, Kempermann G, Thal LJ, Gage FH (1997) Epidermal growth factor and fibroblast growth factor-2 have different effects on neural progenitors in the adult rat brain. J Neurosci 17:5820-5829.

Laywell ED, Rakic P, Kukekov VG, Holland EC, Steindler DA (2000) Identification of a multipotent astrocytic stem cell in the immature and adult mouse brain. Proc Natl Acad Sci USA 97:13883-13888.

Lim DA, Alvarez-Buylla A (1999) Interaction between astrocytes and adult subventricular zone precursors stimulates neurogenesis. Proc Natl Acad Sci USA 96:7526-7531.

Lim DA, Tramontin AD, Trevejo JM, Herrera DG, García-Verdugo JM, Alvarez-Buylla A (2000) Noggin antagonizes BMP signaling to create a niche for adult neurogenesis. Neuron 28:713-726.

Lois C, Alvarez-Buylla A (1994) Long-distance neuronal migration in the adult mammalian brain. Science 264:1145-1148. 
Lois C, Garcia-Verdugo JM, Alvarez-Buylla A (1996) Chain migration of neuronal precursors. Science 271:978-981.

Luskin MB (1993) Restricted proliferation and migration of postnatally generated neurons derived from the forebrain subventricular zone. Neuron 11:173-189.

Magavi SS, Leavitt BR, Macklis JD (2000) Induction of neurogenesis in the neocortex of adult mice. Nature 405:951-955.

Malatesta, P, Hartfuss, E, Gotz M 2000 Isolation of radial glial cells by fluorescent-activated cell sorting reveals a neuronal lineage. Development 127:5253-5263.

Mason HA, Ito S, Corfas G (2001) Extracellular signals that regulate the tangential migration of olfactory bulb neuronal precursors: inducers, inhibitors, and repellents. J Neurosci 21:7654-7663.

Menezes JRL, Smith CM, Nelson KC, Luskin MB (1995) The division of neuronal progenitor cells during migration in the neonatal mammalian forebrain. Mol Cell Neurosci 6:496-508.

Miyata T, Kawaguchi A, Okano H, Ogawa M (2001) Asymmetric inheritance of radial glial fibers by cortical neurons. Neuron 31:727-741.

Morshead CM, Reynolds BA, Craig CG, McBurney MW, Staines WA, Morassutti D, Weiss S, Van der Kooy D (1994) Neural stem cells in the adult mammalian forebrain: A relatively quiescent subpopulation of subependymal cells. Neuron 13:1071-1082.

Nacher J, Rosell DR, McEwen BS (2000) Widespread expression of rat collapsin response-mediated protein 4 in the telencephalon and other areas of the adult rat central nervous system. J Comp Neurol 424:628639.

Noctor SC, Flint AC, Weissman TA, Dammerman RS, Kriegstein AR (2001) Neurons derived from radial glial cells establish radial units in neocortex. Nature 409:714-720.

Nottebohm F (1985) Neuronal replacement in adulthood. In: Hope for a new neurology (Nottebohm F, ed), pp 143-161. New York: New York Academy of Sciences.

Ono K, Tomasiewicz H, Magnuson T, Rutishauser U (1994) N-CAM mutation inhibits tangential neuronal migration and is phenocopied by enzymatic removal of polysialic acid. Neuron 13:595-609.

Pencea V, Bingaman KD, Freedman LJ, Luskin MB (2001a) Neurogenesis in the subventricular zone and rostral migratory stream of the neonatal and adult primate forebrain. Exp Neurol 172:1-16.

Pencea V, Bingaman KD, Wiegand SJ, Luskin MB (2001b) Inf usion of brain-derived neurotrophic factor into the lateral ventricle of the adult rat leads to new neurons in the parenchyma of the striatum, septum, thalamus, and hypothalamus. J Neurosci 21:6706-6717.

Peretto P, Merighi A, Fasolo A, Bonfanti L (1997) Glial tubes in the rostral migratory stream of the adult rat. Brain Res Bull 42:9-21.

Petreanu LT, Alvarez-Buylla A (2001a) Granule cell replacement in the olfactory bulb of adult anosmic mice. Soc Neurosci Abstr 140:15.

Rasika S, Nottebohm F, Alvarez-Buylla A (1994) Testosterone increases the recruitment and/or survival of new high vocal center neurons in adult female canaries. Proc Natl Acad Sci USA 91:7854-7858.

Rasika S, Alvarez-Buylla A, Nottebohm F (1999) BDNF mediates the effects of testosterone on the survival of new neurons in an adult brain. Neuron 22:53-62.

Rousselot P, Lois C, Alvarez-Buylla A (1995) Embryonic (PSA) $\mathrm{N}$-CAM reveals chains of migrating neuroblasts between the latera ventricle and the olfactory bulb of adult mice. J Comp Neurol 351:51-61.

Seri B, Garcia-Verdugo JM, McEwen BS, Alvarez-Buylla A (2001) Astrocytes give rise to new neurons in the adult mammalian hippocampus. J Neurosci 21:7153-7160.

Smith MT, Pencea V, Wang Z, Luskin MB, Insel TR (2001) Increased number of BrdU-labeled neurons in the rostral migratory stream of the estrous prairie vole. Horm Behav 39:11-21.

Tanapat, P, Hastings NB, Reeves AJ, Gould E (1999) Estrogen stimulates a transient increase in the number of new neurons in the dentate gyrus of the adult female rat. J Neurosci 19:5792-5801.

Temple S, Alvarez-Buylla A (1999) Stem cells in the adult mammalian central nervous system. Curr Opin Neurobiol 9:135-141.

Thomas LB, Gates MA, Steindler DA (1996) Young neurons from the adult subependymal zone proliferate and migrate along an astrocyte, extracellular matrix-rich pathway. Glia 17:1-14.

Tomasiewicz H, Ono K, Yee D, Thompson C, Goridis C, Rutishauser U, Magnuson T (1993) Genetic deletion of a neural cell adhesion molecule variant (N-CAM 180) produces distinct defects in the central nervous system. Neuron 11:1163-1174.

Tropepe V, Craig CG, Morshead CM, Van der Kooy D (1997) Transforming growth factor-'61 null and senescent mice show decreased neural progenitor cell proliferation in the forebrain subependyma. J Neurosci 17:7850-7859.

Vescovi AL, Galli R, Gritti A (2001) The neural stem cells and their transdifferentiation capacity. Biomed Pharmacother 55:201-205.

Weickert CS, Webster MJ, Colvin SM, Herman MM, Hyde TM, Weinberger DR, Kleinman JE (2000) Localization of epidermal growth factor receptors and putative neuroblasts in human subependymal zone. J Comp Neurol 423:359-372.

Weiss S, Dunne C, Hewson J, Wohl C, Wheatley M, Peterson AC, Reynolds BA (1996) Multipotent CNS stem cells are present in the adult mammalian spinal cord and ventricular neuroaxis. J Neurosci 16:7599-7609.

Wichterle H, Garcia-Verdugo JM, Alvarez-Buylla A (1997) Direct evidence for homotypic, glia-independent neuronal migration. Neuron 18:779-791.

Wu W, Wong K, Chen JH, Jiang ZH, Dupuls S, Wu JY, Rao Y (1999) Directional guidance of neuronal migration in the olfactory system by the protein Slit. Nature 400:331-336. 